\title{
High-Level Feedback Control with Neural Networks
}


WORLD SCIENTIFIC SERIES IN ROBOTICS AND INTELLIGENT SYSTEMS

Editor-in-Charge: C J Harris (University of Southampton)

Advisor: $\quad$ T M Husband (University of Salford)

Published:

Vol. 1: Genetic Algorithms and Robotics - A Heuristic Strategy for Optimization (Y Davidor)

Vol. 2: Parallel Computation Systems for Robotics: Algorithms and Architectures (Eds. A Bejczy and A Fijany)

Vol. 3: Intelligent Robotic Planning Systems ( $P$ C-Y Sheu and $Q$ Xue)

Vol. 4: Computer Vision, Models and Inspection ( $A$ D Marshall and $R R$ Martin)

Vol. 5: Advanced Tactile Sensing for Robotics (Ed. HR Nicholls)

Vol. 6: Intelligent Control: Aspects of Fuzzy Logic and Neural Nets ( $C J$ Harris, $C$ G Moore and M Brown)

Vol. 7: Visual Servoing: Real-Time Control of Robot Manipulators Based on Visual Sensory Feedback (Ed. K Hashimoto)

Vol. 8: Modelling and Simulation of Robot Manipulators: A Parallel Processing Approach (A Y Zomaya)

Vol. 9: Advanced Guided Vehicles - Aspects of the Oxford AGV Project (Eds. S Cameron and P Probert)

Vol. 10: Cellular Robotics and Micro Robotic Systems ( $T$ Fukuda and $T$ Ueyama)

Vol. 11: Recent Trends in Mobile Robots (Ed. YF Zheng)

Vol. 12: Intelligent Assembly Systems (Eds. M Lee and J J Rowland)

Vol. 14: Intelligent Supervisory Control: A Qualitative Bond Graph Reasoning Approach ( $H$ Wang and $D$ A Linkens)

Vol. 15: Neural Adaptive Control Technology (Eds. R Zbikowski and KJ Hunt)

Vol. 17: Applications of Neural Adaptive Control Technology (Eds. J Kalkkuhl, $K J$ Hunt, $R$ Zbikowski and A Dzielinski)

Vol. 20: Obstacle Avoidance in Multi-robot Systems: Experiments in Parallel Genetic Algorithms (M A C Gill and A Y Zomaya)

Vol. 21: High-Level Feedback Control with Neural Networks ( $Y$ H Kim and F L Lewis)

Forthcoming:

Vol. 13: Sensor Modelling, Design and Data Processing in Confined Environments (MD Adams)

Vol. 16: Advances in Robotics \& Automation for Hazardous Environment (Eds. P Lever and $F Y$ Wang)

Vol. 18: Soft Computing in Systems and Control Technology (Ed. S Tzafestas)

Vol. 19: Adaptive Neural Control of Robotic Manipulators (S S Ge, TH Lee and C J Harris) 
World Scientific Series in Robotics and Intelligent Systems - Vol. 21

\section{High-Level Feedback Control with \\ Neural Networks}

\section{Y. H. Kim \\ F. L. Lewis}

Automation Robotics Research Institute

The University of Texas at Arlington 


\section{Published by}

World Scientific Publishing Co. Pte. Ltd.

P O Box 128, Farrer Road, Singapore 912805

USA office: Suite 1B, 1060 Main Street, River Edge, NJ 07661

UK office: 57 Shelton Street, Covent Garden, London WC2H 9HE

\section{Library of Congress Cataloging-in-Publication Data}

Kim, Y. H. (Young Ho)

High-level feedback control with neural networks / Y. H. Kim, F. L. Lewis.

p. $\quad \mathrm{cm}$. - (World Scientific series in robotics and intelligent systems: vol. 21)

Includes bibliographical references and index.

ISBN 9810233760

1. Feedback control systems. 2. Neural networks (Computer science)
I. Lewis, Frank L.
II. Title. III. Series.

TJ216.K47 1998

629.8'3--dc21

98-33881

CIP

\section{British Library Cataloguing-in-Publication Data}

A catalogue record for this book is available from the British Library.

Copyright $\odot 1998$ by World Scientific Publishing Co. Pte. Ltd.

All rights reserved. This book, or parts thereof, may not be reproduced in any form or by any means, electronic or mechanical, including photocopying, recording or any information storage and retrieval system now known or to be invented, without written permission from the Publisher.

For photocopying of material in this volume, please pay a copying fee through the Copyright Clearance Center, Inc., 222 Rosewood Drive, Danvers, MA 01923, USA. In this case permission to photocopy is not required from the publisher. 


\section{CONTENTS}

Preface

\section{CHAPTER 1 \\ INTRODUCTION}

1.1. Motivation ........................................................................................ 1

1.2. Research Objectives and Organization of Book ……………………….. 3

\section{CHAPTER 2 \\ BACKGROUND}

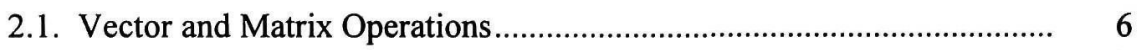

2.2. Practical Stability of Non-linear Systems ............................................... 7

2.3. Neural Network Model............................................................................ 8

2.3.1. Processing Element .................................................................... 9

2.3.2. Multi-layer Neural Network ....................................................... 11

2.3.3. Dynamic Recurrent Neural Network …………………………..... 17

2.4. Fuzzy System and Fuzzy Basis Function............................................... 20

2.4.1. Formulas of Fuzzy System ………………………………..... 21

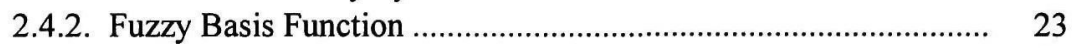

2.4.3. Approximation Properties of Fuzzy System ................................ 25

2.5. Learning Paradigms............................................................................ 27

2.5.1. General Learning.................................................................... 27

2.5.2. Specialized Learning ............................................................... 28

2.5.3. Feedback Error Learning ……………………………………..... 29

2.5.4. Reinforcement Learning ............................................................ $\quad 30$

\section{CHAPTER 3 \\ MULTIPLE MANIPULATORS CONTROL USING NEURAL NETWORKS}

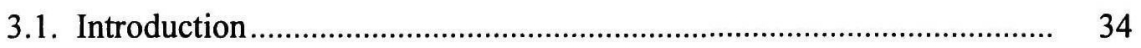

3.2. Multiple Manipulators Models and Properties ………………………..... 36

3.3. Neural Network Coordinated Controller Design .................................... $\quad 40$

3.3.1. Bounding Assumptions and Facts ............................................. $\quad 40$

3.3.2. Controller Structure and Error Dynamics................................... 43 
3.3.3. Stability Analysis................................................................... 44

3.4. Simulation Results.......................................................................... 50

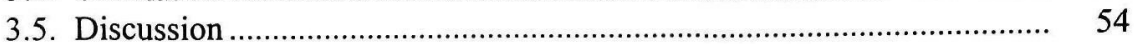

\section{CHAPTER 4 \\ NEURAL NETWORK OUTPUT FEEDBACK CONTROL OF ROBOT MANIPULATORS}

4.1. Introduction ................................................................................... 55

4.2. Robot Dynamics and Properties ........................................................ 57

4.3. Dynamic Neural Network Observer Design ........................................... 58

4.3.1. Observer Structure and Error Dynamics...................................... 58

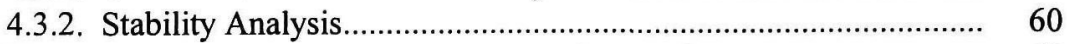

4.4. Neural Network Output Feedback Controller Design ............................ 63

4.4.1. Controller Structure and Error Dynamics.................................... 64

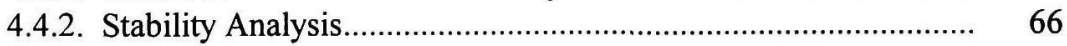

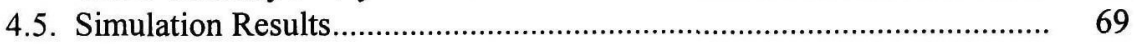

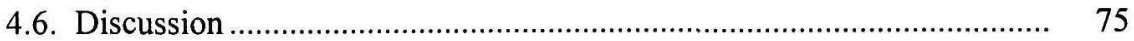

\section{CHAPTER 5 \\ NONLINEAR OBSERVER USING DYNAMIC RECURRENT NEURAL NETWORKS}

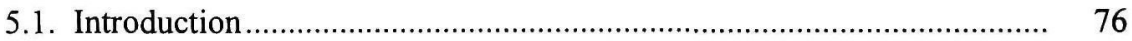

5.2. Non-linear Plant and Observer .......................................................... 79

5.3. Dynamic Neural Network Observer Design ......................................... 82

5.3.1. Observer Structure and Error Dynamics...................................... $\quad 82$

5.3.2. Stability Analysis: SPR Lyapunov Approach............................... $\quad 85$

5.4. Simulation Results............................................................................... 91

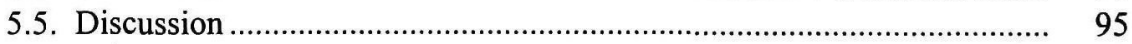

\section{CHAPTER 6 \\ DIRECT REINFORCEMENT LEARNING CONTROL OF NONLINEAR SYSTEMS}

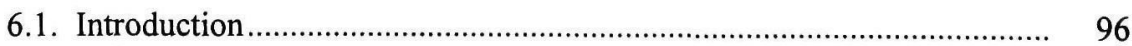

6.2. Reinforcement Neural Controller Design ........................................... 99

6.2.1. Controller Architecture ............................................................ 99

6.2.2. Stability Analysis: Reinforcement Algorithm........................... 102

6.3. Simulation Results........................................................................... 109

6.4. Discussion ................................................................................... 114 


\section{CHAPTER 7 \\ DIRECT REINFORCEMENT FUZZY CONTROL OF NONLINEAR SYSTEMS}

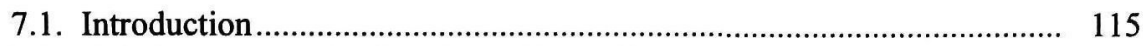

7.2. Reinforcement Adaptive Fuzzy Controller Design.............................. 118

7.2.1. Controller Architecture............................................................ 119

7.2.2. Stability Analysis: Reinforcement algorithm............................. 120

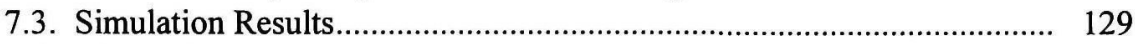

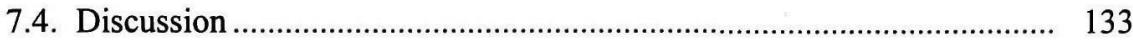

\section{CHAPTER 8 \\ NEURAL FRICTION COMPENSATION FOR HIGH PERFORMANCE}

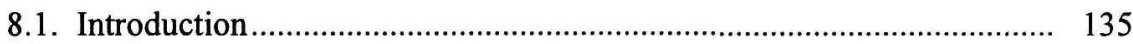

8.2. 1-DOF System and Friction Models.................................................. 137

8.3. Reinforcement Adaptive Learning Controller Design ............................ 139

8.4. Simulation Results........................................................................ 145

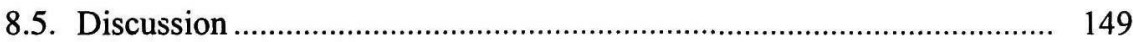

\section{CHAPTER 9 \\ INTELLIGENT OPTIMAL CONTROL OF ROBOT MANIPULATORS}

9.1. Introduction.

9.2. Robot Arm Dynamics and Properties .............................................. 152

9.3. Optimal Computed Torque Controller Design ..................................... 153

9.3.1. Hamilton-Jacobi-Bellman Optimization..................................... 153

9.3.2. Stability Analysis.................................................................. 157

9.4. Neural Optimal Controller Design ................................................. 158

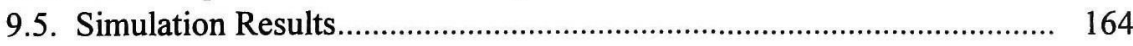

9.6. Discussion .................................................................................... 170

CHAPTER 10

\section{CONCLUSION AND FUTURE RESEARCH}

10.1. General Conclusion 
viii High-Level Feedback Control with Neural Networks

\section{APPENDICES}

APPENDIX A. OPTIMAL CONTROL LAW AND CRITIC

GAIN DERIVATION

APPENDIX B. MULTI-LAYER NEURAL NETWORK WEIGHT

INITIALIZATION ....................................... 178

APPENDIX C. CODE FOR SIMULATION OF INTELLIGENT

CONTROLLERS ........................................ 190

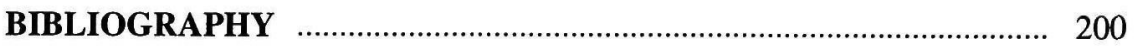

INDEX 


\section{PREFACE}

Conventional control systems are designed using mathematical models of physical systems. A mathematical model, which describes the dynamical behavior of the system, is developed, and then control design techniques are applied to design the appropriate controller. Therefore, the mathematical model must be "simple enough" to be analyzed with available mathematical methods and "accurate enough" to describe the dynamic behavior of the system. Changes in environment and the presence of non-linearities and uncertainties are difficulties to be dealt with by the conventional control engineer.

Intelligent control, using neural networks and fuzzy systems, can be applied to non-linear dynamical systems. In our approach, intelligent control systems are defined as control systems which include low-level feedback control and highlevel supervision to monitor the performance of the system output. As intelligent control methods have found their way into standard practice, they have opened the door to a wide spectrum of non-linear control applications by overcoming changes in environment, non-linearities and uncertainty in the system.

When intelligent control methods are incorporated into the feedback path in the overall system, it has often been the case that no non-linear analysis was performed to verify the behavior of the closed-loop system and quite frequently no implementation and experimental evaluation was conducted. Training algorithms (on-line versus off-line) were also misunderstood. This has limited intelligent control applications, especially in hardware control demonstrations.

This monograph proposes special learning algorithms for the control of uncertain non-linear systems. Instead of the normal back-propagation learning or delta-learning rule used in the neural network literature, adaptive-learning rules are derived using the Lyapunov method to adjust the weights of the neural network or to adjust the control representative values in fuzzy systems. Both system stability and error convergence can then be guaranteed. Stability of the overall system is certainly a prime requirement that must be met before thinking of real-world applications.

The neural and fuzzy controllers discussed in this book have a number of application benefits. They will perform effectively in changing environments 
because of their ability to deal with unseen changes in mechanical systems and their model-free design will allow them to be used in many different types of mechanical systems.

When all the states of the controlled system are not available as measurements due to economic or physical constraints, a dynamic recurrent neural network need to be used for estimating the missing system states. The estimated states will be used as system states for feedback control scheme. The overall control structure requires a sort of hierarchical structure that can contain neural network as higher levels of abstraction.

The reinforcement learning methods provide a learning feature driven by the basic success or failure record of the controlled system. The key point is that the performance indicator (critic) of the controlled system is simple and that these simple signals tune or adapt a neural network controller so that its performance improves over time dramatically. Due to the simple performance indicator, the computational requirements of a neural network can be reduced significantly. It can be viewed as a hierarchical system with performance evaluator for the closedloop system.

It is evident that if the plant has additional complications or uncertainties, more hierarchical structure must be added to the control system. It is important to provide a smooth transition between the regulator functions of the feedback controller and the supervisory functions of the human operator. In that direction, Hamilton-Jacobi-Bellman optimal neural network control is designed to provide a higher-level controllers with hierarchical designs that are similar structure to controllers designed using computer science techniques. It has shown smooth interface between feedback loops and the human user.

The material presented in this book basically follows research efforts during the previous two years at Automation and Robotics Research Institute at the University of Texas, Arlington. We would like to thank the National Science Foundation for the financial support during this research. 